\title{
Incremental analysis for the performance evaluation of material handling equipment: A
} holistic approach

\author{
Bipradas Bairagi $^{a^{*}}$, Balaram Dey ${ }^{b}$ and Bijan Sarkar
}

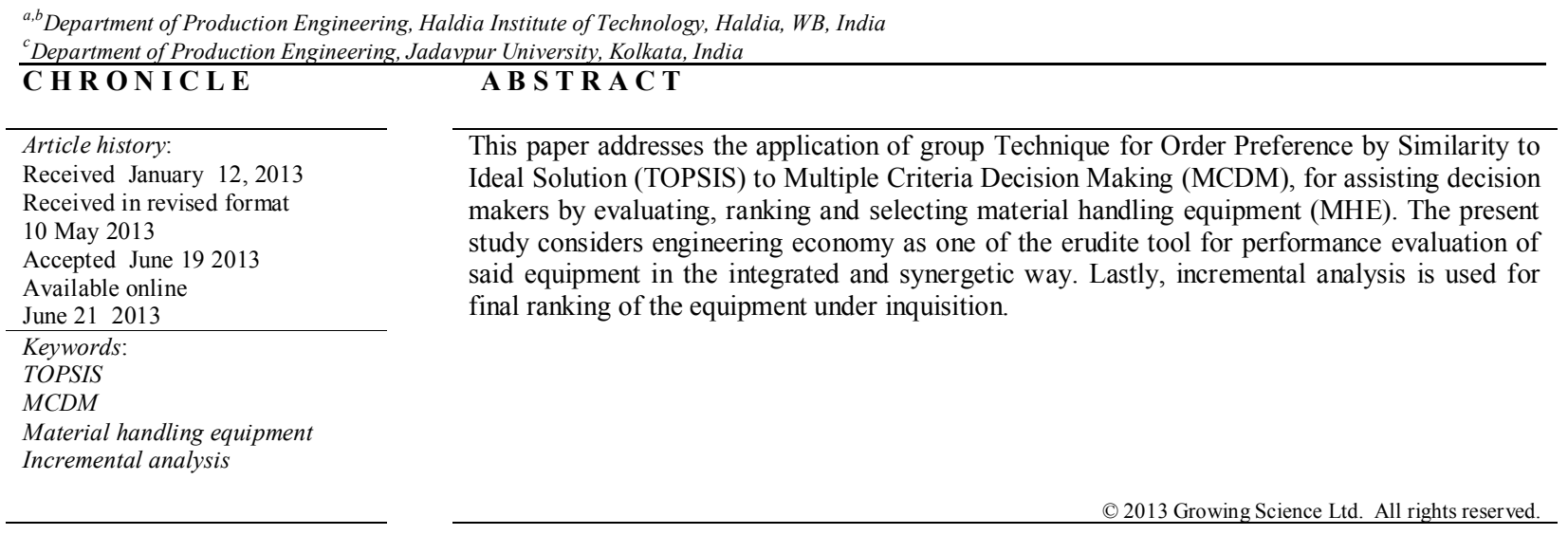

\section{Introduction}

The movement of material, the basic function of material handling, is as old as man but the requirement of material handling in industry began due to industrial revolution in late eighteenth to late nineteenth centuries. The industries, construction projects, supermarket, ports, hospitals, mills etc. are engaged in movement of material from one place to another. The basic aim of using a material handling equipment (MHE) is to handle raw materials, finished or semi-finished products, work-in-progress, machineries and tools. In industry, use of material handling equipment requires cost, time and space; increases productivity and capacity; decreases probable risk and damage of material; improves customer service and working condition (Sharma, 1999). Material handling (MH) accounts for $30-75 \%$ of the total cost of a product, and proficient material handling can be liable for plummeting the manufacturing system operations cost by 15-30\% (Sule, 1994). The material handling system (MHS) plays a critical role in manufacturing systems. When inefficiently planned, the MHS undeniably can interfere with the overall performance of the system and lead to extensive

* Corresponding author. Tel: +91 8926506451

E-mail addresses: bipradas_bairagi@yahoo.co.in (B. Bairagi)

C) 2013 Growing Science Ltd. All rights reserved. doi: $10.5267 /$ j.uscm.2013.06.003 
fatalities in productivity and competitiveness, and to incongruously long lead times. Thus, to evade such difficulty, MHS design must be incorporated into the overall design of the manufacturing system, which centers on the selection of machines and the allocation of operations to the machines.

Material handling equipment have wide range attribute/characteristics. Manufactures possess variable performance attributes. Therefore, it is one of the extremely hardest tasks to select the optimal material handling equipment in MCDM environment. In the present paper, an effort is done for solving problems regarding material handling equipment selection by performance evaluation through incremental analysis under MCDM environment. An algorithm is proposed for the same. A problem on MHE is cited and solved for the intension of better clarification and explanation that justifies the applicability of the proposed algorithm for the performance evaluation, ranking and selection of material handling equipment.

A decision-making problem with at least two conflicting criteria and at least two alternatives is known as multi-criteria decision-making (MCDM) problem. Several techniques/approaches are employed to select the best alternative from a real set of feasible alternatives by solving the MCDM problem (Karande \& Chakraborty, 2013). TOPSIS is one of the popular approaches of solving MCDM problem (Dey et al., 2012). TOPSIS was proposed by Hwang and Yoon (1981). In TOPSIS method, the best solution is nearest to positive ideal solution which is associated to maximum value of benefit criteria and minimum value of cost criteria (Kabir \& Hasin, 2012).

The compromise/optimal solution can be termed as the solution with the least Euclidean distance from the positive ideal solution and the farthest distance from the negative ideal solution (Goyal \& Grover, 2012). In the current work, incremental analysis of benefit and cost criteria values as well as benefit cost ratio has also been considered in finding the best solution. Benefit-cost ratio is measured as a critical tool in MCDM (Shih, 2008). The choice of alternatives is made according to the highest benefit-cost ratio. Bernhard and Canada (1990) argue that the use of benefit cost ratio by Saaty (1980) would not necessarily give an optimal solution. Hence, an incremental analysis of benefit and cost criteria value is indispensable and imperative for the best and optimal solution.

The rest of the paper is decorated as follows. Section 2 furnishes a details literature review on MHE. Section 3 presents a case study. Section 4 proposes an algorithm. Section 5 is equipped with calculation with result and discussion. Finally, section 6 is employed for some essential conclusion on the work.

\section{Literature review}

Material handling equipment selection is nowadays a subject matter of major importance in industries, and profoundly premeditated by the academicians and researchers. For the duration of the last few decades, diverse approaches have been anticipated to assess, select and supervise the optimal MHE while considering multiple conflicting attribute, employing methodologies and techniques from various topics of computational intelligence. A broad literature survey shows that numerous attempts have already been made to prove the usefulness and potentiality of different MCDM techniques in this sphere of influence.

Ribeiro and Pradin (1993) presented a two-phase methodology for the selection of production cells. This methodology permits the selection of machines which have to be assigned to the cell, assigns parts to machines, and yields a partition of parts and machines. Gupta and Dutta (1994) proposed a methodology that adopted five key product variables and different operations and sub-operations for MHE. In this methodology material handling system is selected through a weighted rating method. Rembold and Tanchoco (1994) presented a good review of the literature on the former aspect of MHE. Atmani and Dutta (1996) proposed a 0-1 integer-programming model to select a material 
handling equipment by maximizing an adaptability factor as the ratio of basic movements that are required by a new product to those available in the current manufacturing logistics systems. Bhattacharya et al. (2002) proposed an AHP based paradigm for material handling equipment selection under multi criteria decision making (MCDM) environment. Chittratanawat and Noble (1999) developed an integrated facility design approach, which includes departmental location, qualitative relationships, pickup/drop-off point locations, and material handling equipment selection in a single formulation. The integrated model was formulated as a nonlinear mixed integer programming model to minimize the total cost of actual material handling.

Castillo and Peters (2002) developed an integrated manufacturing system design model. The integration of unit load and material handling considerations in a facility layout is presented. This integration is based on a stochastic model that captures the operational characteristics of the manufacturing system and a non-linear mixed- integer program that incorporates a department formation and facility layout. Paulo et al. (2002) presented a new framework for the joint consideration of the operation allocation and the material handling system selection problems. They presented two 0-1 integer programming models, one for operation allocation (OA), and the second, for material handling system selection (MHSS), which are solved sequentially.

Lashkari et al. (2004) developed a modified 0-1 integer programming model that was solved iteratively to find a locally optimal solution. The output of the OA model is in the form of the manufacturing operations to be performed at each machine. This information grants the input to the material handling system selection model which now selects the material handling equipment to transport a part from one machine to another. This iterative process continues until an overall optimal solution is obtained. Paul Fulford et al. (2007) made the technology development, the driving requirements and the test results. They demanded that the technology of material handling of Paul Fulford et al would be superior to the existing technology.

Sujono and Lashkari (2007) developed a 0-1 integer programming model to assign material handling equipment to transport the part from machine to machine as well as to handle a part a given machine. The selection was based on the compatibility between the material handling equipment and parts. Raman et al. (2009) developed two-step analytical approaches to find out the quantity of material handling equipment (MHE) essential for effective handling of products among facilities. In the first step, a preliminary solution is achieved by considering the time necessary for loading and unloading of products, loaded traveling, empty traveling and breakdown of MHE. A comprehensive model, which assimilates both operational and cost performance factors such as utilization of MHE, work-inprocess at the MHS and life-cycle cost, is then utilized to rank alternatives that are generated from the preliminary solution.

\section{Case Study}

In order to analyze the practice oriented structure along with conceptual analysis of decision making methodologies, a case study including the practice of these methodologies will be presented in this section for the problem of material handling selection. A material handling selection problem has been taken for the case study. Performance of five material handling equipment namely MHE1, MHE2 MHE3, MHE4 \& MHE5 are to be evaluated by five decision makers (DMs) to handle a particular type of material. The decision makers consider four objective criteria and three subjective criteria as shown Table 1. Cost, Macro Movement, Micro-Movement and Load carrying capacity are objective criteria, measured by crisp value. Whereas Shape, Condition, flexibility are subjective criteria and evaluated by human perception, feeling and experience. Cost is non benefit criterion where other six criteria are of benefit category. 
Table 1

Objective and Subjective criteria

\begin{tabular}{|c|c|c|c|c|c|c|}
\hline \multicolumn{4}{|c|}{ Objective Criteria } & \multicolumn{3}{|c|}{ Subjective Criteria } \\
\hline $\mathrm{C} 1$ & $\mathrm{C} 2$ & $\mathrm{C} 3$ & $\mathrm{C} 4$ & $\mathrm{C} 5$ & C6 & C7 \\
\hline $\begin{array}{l}\text { Cost } \\
\text { ( Rs) }\end{array}$ & $\begin{array}{c}\text { Macro } \\
\text { Movement } \\
(\mathrm{mm})\end{array}$ & $\begin{array}{c}\text { Micro- } \\
\text { Movement } \\
(\mu \mathrm{m})\end{array}$ & $\begin{array}{l}\text { Load carrying } \\
\text { capacity } \\
\text { (Kg) }\end{array}$ & Shape & Condition & flexibility \\
\hline
\end{tabular}

\section{Proposed Algorithm}

The following algorithm is proposed to select the best alternative by solving the above problem.

Step-1: Construction of a decision matrix $D^{h}$ by each DM, $D^{h}$ is represented as follows.

$$
D^{h}=\begin{gathered}
A_{1} \\
A_{2} \\
\ldots \\
A_{i} \\
\ldots \\
A_{m}
\end{gathered}\left[\begin{array}{cccccc}
x_{11}^{h} & x_{12}^{h} & \ldots & x_{1 j}^{h} & \ldots & x_{1 n}^{h} \\
x_{21}^{h} & x_{22}^{h} & \ldots & x_{2 j}^{h} & \ldots & x_{2 n}^{h} \\
\ldots & \ldots & \ldots & \ldots & \ldots & \ldots \\
x_{i 1}^{h} & x_{i 2}^{h} & \ldots & x_{i j}^{h} & \ldots & x_{i n}^{h} \\
\ldots & \ldots & \ldots & \ldots & \ldots & \ldots \\
x_{m 1}^{h} & x_{m 2}^{h} & \ldots & x_{m j}^{h} & \ldots & x_{m n}^{h}
\end{array}\right]
$$

Where $A_{i}$ denotes the $\mathrm{i}^{\text {th }}$ alternative, $\mathrm{i}=1,2, . ., \mathrm{m} ; \mathrm{m}$ is number of alternatives; $C_{j}$ denotes $\mathrm{j}^{\text {th }}$ criterion or attribute, $\mathrm{j}=1,2, \ldots, \mathrm{n} ; \mathrm{n}$ is the number of criteria; $x_{i j}^{h}$ is the performance rating of alternative $A_{i}$ with respect to criterion $C_{j}$ by $\mathrm{h}^{\text {th }}$ decision maker, $\mathrm{h}=1,2, \ldots, \mathrm{H} ; \mathrm{H}$ is the total number of DMs. The criteria are divided into two parts one is benefit criteria and the other is cost criteria. Benefit criteria is one whose higher value is desirable and cost criteria is one whose lower value is desirable. Let the number of benefit criteria is $\mathrm{p}$ and the number of cost criteria is $\mathrm{q}$, so that $\mathrm{p}+\mathrm{q}=\mathrm{n}$.

Step-2: Construction of normalized decision matrix $T_{b}^{h}$ by each DM, b stands for the benefit criteria.

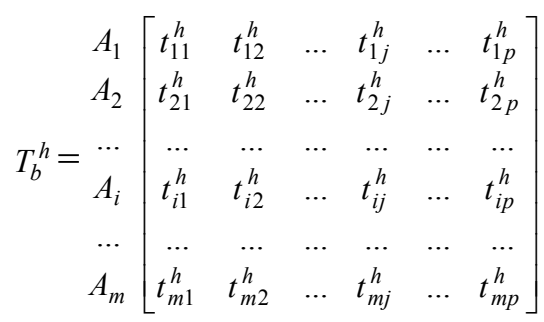

Where $t_{i j}^{h}$ the normalized value is obtained by any transformation of the column of the benefit criteria of $D^{h}$ keeping $0 \leq t_{i j}^{h} \leq 1$. The normalized value $\mathrm{t}_{\mathrm{ij}}^{\mathrm{h}}$ is determined by the formula.

$t_{i j}^{h}=\frac{x_{i j}^{h}}{\sqrt{\sum_{i=1}^{n} x_{i j}^{h}}}$, where $\mathrm{i}=1, \ldots, \mathrm{m}$. and $\mathrm{j}=1, \ldots . \mathrm{p}$.

Step3: Assigning of a weight vector, $W_{b}^{h}, \mathrm{~h}=1,2 \ldots \mathrm{H}$; for the benefit criteria by each DM.

$W_{b}^{h}=\left[w_{1}^{h}, w_{2}^{h} \ldots w_{p}^{h}\right]$, where $\sum_{j=1}^{p} w_{j}^{h}=1$ and $\mathrm{j}=1,2, \ldots, \mathrm{p}$ 
Step 4: Construction of modified, normalized and weighted decision matrix $U_{b}^{h}$ by each DM

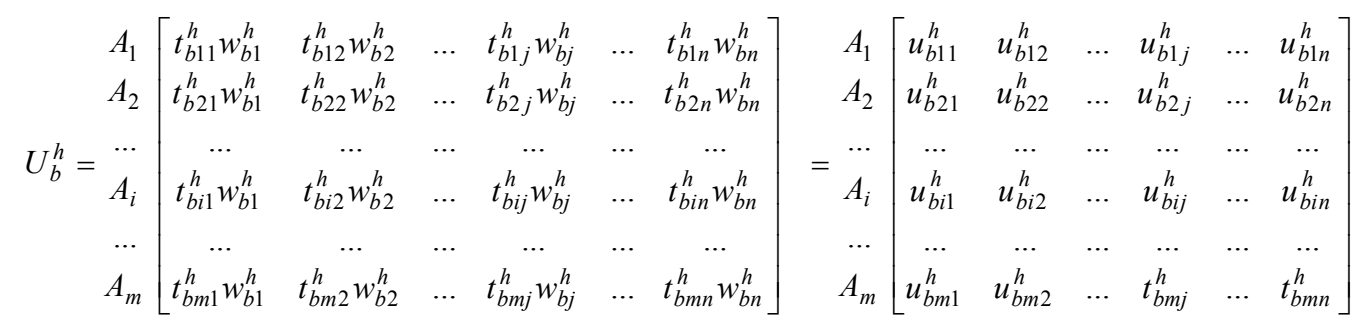

The value of $u_{b i j}^{h}$ lies between 0 and 1 that is $0 \leq u_{b i j}^{h} \leq 1 . \mathrm{i}=1,2, \ldots, \mathrm{m} . \quad \mathrm{j}=1,2, \ldots, \mathrm{p}$.

Step 5: Determination of ideal solution $\left(V_{b}^{h+}\right)$ and negative ideal solution $\left(V_{b}^{h-}\right)$

$V_{b}^{h+}=\left[v_{b 1}^{h+} \ldots . v_{b p}^{h+}\right]\left\{\max v_{b i j}^{h+} ; \mathrm{i}=1, \ldots, \mathrm{m} . \quad \mathrm{j}=1,2 \ldots \mathrm{p}\right.$.

$V_{b}^{h-}=\left[v_{b 1}^{h-} \ldots . . v_{b p}^{h-}\right]\left\{\min v_{b i j}^{h+} ; \mathrm{i}=1,2, \ldots, \mathrm{m} . \quad \mathrm{j}=1,2 \ldots \mathrm{p}\right.$.

Step 6: Calculation of separation measures $S_{b i}^{h+}$ and $S_{b i}^{h-}$ of the benefit criteria from PIS and NIS firstly individual separation measures then group separation measure by decision makers. The following formulae are for individual separation measures.

$$
\begin{gathered}
S_{b i}^{h+}=\left\{\sum_{j=1}^{n}\left|v_{b i j}^{h}-v_{b i j}^{h+}\right|^{p}\right\}^{1 / p} \mathrm{i}=1,2,3, \ldots, \mathrm{m} . \quad \mathrm{p} \geq 1 \text { and is an integer. } \\
S_{b i}^{h-}=\left\{\sum_{j=1}^{n}\left|v_{b i j}^{h}-v_{b i j}^{h-}\right|^{p}\right\}^{1 / p} \mathrm{i}=1,2,3, \ldots, \mathrm{m} . \quad \mathrm{p} \geq 1 \text { and is an integer. }
\end{gathered}
$$

When $p$ is taken as $\mathrm{p}=2$ and distances are called Euclidean distances and the above equation are written as

$S_{b i}^{h+}=\left\{\sum_{j=1}^{n}\left|v_{b i j}^{h}-v_{b i j}^{h+}\right|^{2}\right\}^{1 / 2}$ where $\mathrm{i}=1,2,3, \ldots, \mathrm{m} ; \mathrm{p}$ is an integer and having the value $\geq 1$
$S_{b i}^{h-}=\left\{\sum_{j=1}^{n}\left|v_{b i j}^{h}-v_{b i j}^{h-}\right|^{2}\right\}^{1 / 2} \quad$ where $\mathrm{i}=1,2,3, \ldots, \mathrm{m} ; \mathrm{p}$ is an integer and having the value $\geq 1$

Step 7: Determination of group separation measure $\bar{S}_{b i}^{h+}$ and $\bar{S}_{b i}^{h-}$ from the above calculated value of individual separation measure of alternatives. In order to calculate group separation measure the following formulae are used.

$\bar{S}_{b i}^{h+}=S_{b i}^{1+} \otimes S_{b i}^{1+} \otimes \ldots \ldots . \otimes S_{b i}^{h+}$ where, $\mathrm{i}=1,2, \ldots, \mathrm{m}$.

$\bar{S}_{b i}^{h-}=S_{b i}^{1-} \otimes S_{b i}^{2-} \otimes \ldots \ldots . \otimes S_{b i}^{h-} \quad$ where, $\mathrm{i}=1,2, \ldots, \mathrm{m}$

Geometrical mean (GM) is preferred to arithmetic mean (AM) for performing the above operation. If geometrical mean (GM) is followed then the abovementioned operations can be represented as follows.

$$
\bar{S}_{b i}^{+}=\left\{\prod_{h=1}^{h} S_{b i}^{h+}\right\}^{1 / h} ; \text { where }, i=1, \ldots . . m ;
$$


$\bar{S}_{b i}^{-}=\left\{\prod_{h=1}^{h} S_{b i}^{h-}\right\}^{1 / h} ;$ where $, i=1, \ldots . . m ;$

$\bar{S}_{b i}^{+}$is group positive separation measure and $\bar{S}_{b i}^{-}$is group negative separation measure.

Step 8: Finding of group relative closeness $\bar{C}_{b i}^{*}$ to the ideal solution from the group separation measure $S_{b i}^{h+}$ and $\bar{S}_{b i}^{h-}$ for benefit criteria for each alternative. Group relative closeness can be represented as follows.

$\overline{C_{b i}^{*}}=\frac{\overline{S_{b i}^{-}}}{\overline{S_{b i}^{+}+S_{b i}^{-}}}$

The value of the relative closeness $\bar{C}_{b i}^{*}$ lies between 0 and 1 i.e. $0 \leq \bar{C}_{b i}^{*} \leq 1$. It should be noted the greater the value of the relative closeness $\bar{C}_{b i}^{*}$, the performance of the concerned alternative will be better.

Step 9: Assessment of utility for cost criteria by each decision maker (DM). True cost or monetary values are directly used for evaluation. If more than one cost items are there then they are combined for the evaluation. Assessment of utility for cost criteria is done by DMs to incorporate the attitude towards risk which is represented in the utility function as follows.

$U_{c i}^{h}=U\left(T_{c i}^{h}\right)=T\left\{1-e^{-\frac{T_{c i}^{h}}{T}}\right\}$

where, $T_{c i}^{h}$ is total cost of the alternative $\boldsymbol{i}$ and ' $\mathrm{T}$ ' is the risk tolerance of DMs. Equation (25) is frequently considered to fit a risk-averse individual in decision making. A large aversion to risk corresponds to a small value of $\mathrm{T}$, whereas a small aversion to risk corresponds to a large value of $\mathrm{T}($ Hillier and Hillier, 2003).

Step 10: Determination of utility index by using utility by each DM. For incremental analysis the utility information should be less than 1 . This is done by dividing the utilities by maximum value of their cost column wise which can be expressed as

$U_{c i}^{h^{\prime}}=\frac{U_{c i}^{h}}{\max R_{c i}^{h}} ;$ where $, i=12.1 \ldots, m$. and $0 \leq U_{c i}^{h^{\prime}} \leq 1$

Step 11: Calculation of group utility indices $U_{c i}^{h}$ by using utility indices and the following expression of Geometrical Mean (GM) for each alternative.

$\bar{U}_{c i}^{h^{\prime}}=\left\{\prod_{h=1}^{h} U_{c i}^{h^{\prime}}\right\}^{1 / h}$, where, $i=1,2, \ldots, m ; h=1,2, h$;

Step 12: Rearranging of alternatives according to their values of utility indices in ascending order.

$\left(\overline{U_{c}^{h^{\prime}}}\right)_{\min } \leq---\leq\left(\overline{U_{c}^{h^{\prime}}}\right)_{\max }$

Step 13: Determination of the differences in benefits $\Delta \bar{C}_{b i}^{*}$, and that of in corresponding group utility indices $\Delta \bar{U}_{c i}$ from two consecutive alternatives in step 12 can be obtained by the following equations.

$$
\begin{aligned}
& \Delta \bar{C}_{b i}^{*}=\left(\overline{C_{b}^{*}}\right)_{\text {last }}-\left(\overline{C_{b}^{*}}\right)_{2 \text { nd. from.last }} \text { etc. } \\
& \Delta \overline{U_{c i}^{h^{\prime}}}=\left(\overline{U_{c}^{h^{\prime}}}\right)_{\max }-\left(\overline{U_{c}^{h^{\prime}}}\right)_{\min }
\end{aligned}
$$


Step14: Now the ratio of $\Delta \bar{C}_{b i}^{*} / \Delta \bar{U}_{c i}$ is calculated. It is called benefit cost ratio.

$$
\text { Benefit }- \text { Cost Ratio }=\frac{\Delta \overline{C_{b i}^{*}}}{\Delta \overline{U_{c i}}}
$$

If the value of the ratio $\Delta \bar{C}_{b i}^{*} / \Delta \bar{U}_{c i}$ be greater than unity, then the later one between the alternatives being compared is taken; if the value of the ratio be less than unity, then the former one between the alternatives being compared is taken. If the value of the ratio is negative the former alternative is considered and the later one is rejected.

Step 15: Selection of the best alternative from above incremental analysis.

\section{Calculation and discussion}

Decision matrices are constructed by DMs and are shown in Table 2 for DM1.

Table 2

Formation of decision matrix by the DM1

\begin{tabular}{llllllll}
\hline MHEi & F1 & F2 & F3 & F4 & F5 & F6 & F7 \\
\hline MHE 1 & 234000 & 1.00 & 1.00 & 1.00 & 1.00 & 1.00 & 1.00 \\
MHE 2 & 312000 & 0.33 & 0.20 & 3.00 & 0.33 & 3.00 & 3.00 \\
MHE 3 & 427000 & 0.15 & 3.00 & 0.20 & 0.15 & 0.15 & 0.20 \\
MHE 4 & 274000 & 0.20 & 0.33 & 0.15 & 0.50 & 0.50 & 0.15 \\
MHE 5 & 331000 & 0.50 & 5.00 & 0.17 & 0.33 & 0.33 & 0.33 \\
\hline
\end{tabular}

Decision matrices varies DM to DM due to existence of subjective criteria. Normalization of decision matrices is carried out by using Eqn. 3. Benefit criteria and cost criteria are assessed separately. Ideal Solution (PIS) and Negative Ideal Solution (NIS) are calculated using Eqs. (6-7) and is shown in Table 3. Calculation of separation measure of benefit criteria is calculated by using Eqs. (8-9) and is shown in Table 4. Calculation of group separation measures for benefit criteria is calculated by using Eqs. (12-13) and is shown in Table 5. Relative closeness is determined using Eq. (16) and is shown in Table 6. Utilities, Utility Indices and group utility are computed by using Eqs. (17-19), respectively and are shown in Table 7 and Table 8 respectively. In Table 9 incremental analysis is shown between relative closeness calculated from benefit criteria and group utility indices calculated from cost criteria. The material handling equipment (MHE) is arranged according to their value of group utility indices in descending order as

$$
\text { MHE1 }>\text { MHE2 }>\text { MHE5 }>\text { MHE3 }>\text { MHE4. }
$$

The difference in the value of relative closeness of two consecutive MHE3 and MHE4 is calculated by subtracting the relative closeness of MHE4 from that of MHE3 and so on. Similarly the difference in group utility indices between MHE3 and MHE4 is computed and so on. Now the ratio of difference in relative closeness and group utility indices are successively determined between MHE3 \& MHE4, MHE5 \&MHE3, MHE2 \& MHE5, and MHE1 \& MHE2. The benefit-cost ratio between MHE4 and MHE3 is 6.1902 which is greater than 1. Therefore, MHE3 is accepted and MHE4 is rejected. Similarly, Benefit cost ratio is carried out between MHE5 and MHE 3, MHE2 and MHE 5, MHE1 and MHE2. In each case the benefit cost ratio is found to be always greater than 1 (unity) and the degree of preference between the concerned material handling equipment are established as.

\section{MHE3 $>$ MHE 4 MHE5 $>$ MHE 3 MHE2 > MHE 5 MHE1 > MHE 2}

From the four relations with respect to benefit-cost ratio it is clear that MHE1 is the best and is regarded as the optimal material handling equipment. 
Table 3

Determination of Ideal Solution (PIS) and Negative Ideal Solution (NIS)

\begin{tabular}{|c|c|c|c|c|c|}
\hline$V_{b}^{1+}=\{0.3138$ & 0.1569 & 0.1170 & 0.0627 & 0.0496 & $0.1737\}$ \\
\hline$V_{b}^{2+}=\{0.0336$ & 0.0672 & 0.2256 & 0.2016 & 0.2232 & $0.1504\}$ \\
\hline$V_{b}^{3+}=\{0.0300$ & 0.3000 & 0.0996 & 0.2700 & 0.2989 & $0.2014\}$ \\
\hline$V_{b}^{4+}=\{0.0760$ & 0.1267 & 0.1418 & 0.3802 & 0.0841 & $0.0608\}$ \\
\hline$V_{b}^{5+}=\{0.0168$ & 0.0398 & 0.0538 & 0.5883 & 0.1302 & $0.0438\}$ \\
\hline$V_{b}^{1-}=\{0.0485$ & 0.0056 & 0.0062 & 0.0097 & 0.0027 & $0.0097\}$ \\
\hline$V_{b}^{2-}=\{0.0052$ & 0.0024 & 0.0020 & 0.0312 & 0.0120 & $0.0080\}$ \\
\hline$V_{b}^{3-}=\{0.0046$ & 0.0011 & 0.0054 & 0.0418 & 0.0160 & $0.0107\}$ \\
\hline$V_{b}^{4-}=\{0.0118$ & 0.0045 & 0.0090 & 0.0589 & 0.0045 & $0.0032\}$ \\
\hline$V_{b}^{5-}=\{0.0034$ & 0.0028 & 0.0023 & 0.0910 & 0.0070 & $0.0023\}$ \\
\hline
\end{tabular}

\section{Table 4}

Calculation of separation measure $\left(S_{b i}^{k+}\right.$ and $\left.S_{b i}^{k-}\right)$ of benefit criteria by each DM

\begin{tabular}{ccllc}
\hline$S_{1}^{1+}=0.1905$ & $S_{1}^{1-}=0.2767$ & $S_{1}^{3+}=0.2508$ & $S_{1}^{3-}=0.2516$ & $S_{1}^{5+}=0.1012$ \\
\hline$S_{2}^{1+}=0.2734$ & $S_{2}^{1-}=0.1779$ & $S_{2}^{3+}=0.0782$ & $S_{2}^{3-}=0.3456$ & $S_{2}^{5+}=0.3924$ \\
\hline$S_{3}^{1+}=0.2540$ & $S_{3}^{1-}=0.1427$ & $S_{3}^{3+}=0.4109$ & $S_{3}^{3-}=0.0858$ & $S_{3}^{5+}=0.5144$ \\
\hline$S_{4}^{1+}=0.3386$ & $S_{4}^{1-}=0.0173$ & $S_{4}^{3+}=0.3925$ & $S_{4}^{3-}=0.0377$ & $S_{4}^{5+}=0.1440$ \\
$S_{5}^{1+}=0.2528$ & $S_{5}^{1-}=0.1855$ & $S_{5}^{3+}=0.3618$ & $S_{5}^{3-}=0.1000$ & $S_{5}^{5+}=0.3205$ \\
$S_{1}^{2+}=0.2409$ & $S_{1}^{2-}=0.2057$ & $S_{1}^{4+}=0.1551$ & $S_{1}^{4-}=0.3309$ & $S_{1}^{5-}=0.4991$ \\
$S_{2}^{2+}=0.3016$ & $S_{2}^{2-}=0.0703$ & $S_{2}^{4+}=0.2852$ & $S_{2}^{4-}=0.1194$ & $S_{2}^{5-}=0.4456$ \\
$S_{3}^{2+}=0.3081$ & $S_{3}^{2-}=0.2164$ & $S_{3}^{4+}=0.6591$ & $S_{3}^{4-}=0.1522$ & $S_{3}^{5-}=0.0467$ \\
$S_{4}^{2+}=0.2929$ & $S_{4}^{2-}=0.0282$ & $S_{4}^{4+}=0.3688$ & $S_{4}^{4-}=0.0235$ & $S_{4}^{5-}=0.0237$ \\
$S_{5}^{2+}=0.0720$ & $S_{5}^{2-}=0.0969$ & $S_{5}^{4+}=0.2518$ & $S_{5}^{4-}=0.1738$ & $S_{5}^{5-}=0.2068$ \\
\hline
\end{tabular}

\section{Table 5}

Calculation of group separation measures $S_{b i}^{k+}$ and $S_{b i}^{k-}$ for benefit criteria by each DM

$\begin{array}{ll}S_{b 1}^{+}=[0.1905 \times 0.2409 \times 0.2504 \times 0.1551 \times 0.1012]^{1 / 5}=0.1784 & S_{b 2}^{+}=[0.2734 \times 0.3016 \times 0.0782 \times 0.2852 \times 0.3924]^{1 / 5}=0.2353 \\ S_{b 3}^{+}=[0.2540 \times 0.3081 \times 0.4109 \times 0.6591 \times 0.5144]^{1 / 5}=0.4050 & S_{b 4}^{+}=[0.3386 \times 0.2929 \times 0.3925 \times 0.3688 \times 0.1440]^{1 / 5}=0.2905 \\ S_{b 5}^{+}=[0.2528 \times 0.0720 \times 0.3618 \times 0.2518 \times 0.3205]^{1 / 5}=0.2227 & S_{b 1}^{-}=[0.2767 \times 0.2057 \times 0.2516 \times 0.3309 \times 0.4991]^{1 / 5}=0.2984 \\ S_{b 2}^{-}=[0.1779 \times 0.0703 \times 0.3456 \times 0.1194 \times 0.5456]^{1 / 5}=0.1872 & S_{b 3}^{-}=[0.1427 \times 0.2164 \times 0.0858 \times 0.1522 \times 0.0467]^{1 / 5}=0.1135 \\ S_{b 4}^{-}=[0.0173 \times 0.0282 \times 0.0377 \times 0.0235 \times 0.0237]^{1 / 5}=0.0252 & S_{b 5}^{-}=[0.1855 \times 0.0969 \times 0.1000 \times 0.1738 \times 0.2068]^{1 / 5}=0.1452\end{array}$

Table 6

Determination of relative closeness $\left(\bar{C}_{b i}^{*}\right)$

$$
\begin{gathered}
\bar{C}_{b 1}^{*}=\{0.2984 /(0.2984+0.1784)\}=0.6258 \bar{C}_{b 2}^{*}=\{0.1872 /(0.1872+0.2353)\}=0.4431 \\
\bar{C}_{b 3}^{*}=\{0.1135 /(0.1135+0.4050)\}=0.2189 \bar{C}_{b 4}^{*}=\{0.0252 /(0.0252+0.2905)\}=0.0798 \\
\bar{C}_{b 5}^{*}=\{0.1452 /(0.1452+0.2214)\}=0.3961
\end{gathered}
$$


Table 7

Utilities and Utility Indices

\begin{tabular}{ccccccccccccc}
\hline & & \multicolumn{2}{c}{ DM1 } & \multicolumn{2}{c}{ DM2 } & \multicolumn{2}{c}{ DM3 } & \multicolumn{2}{c}{ DM4 } & \multicolumn{2}{c}{ DM5 } \\
& & \multicolumn{2}{c}{$\begin{array}{c}\mathrm{T}=1,500,000 \\
\text { Utility }\end{array}$} & $\begin{array}{c}\text { Utility } \\
\text { Index }\end{array}$ & \multirow{2}{*}{ Utility } & $\begin{array}{c}\text { Utility } \\
\text { Index }\end{array}$ & Utility & $\begin{array}{c}\text { Utility } \\
\text { Index }\end{array}$ & Utility & $\begin{array}{c}\text { Utility } \\
\text { Index }\end{array}$ & Utility & $\begin{array}{c}\text { Utility } \\
\text { Index }\end{array}$ \\
\hline MHE1 & 427000 & 371603 & 0.8703 & 359293 & 0.8414 & 384496 & 0.9005 & 347536 & 0.8139 & 392525 & 0.9193 \\
MHE2 & 331000 & 297024 & 0.6956 & 289273 & 0.6775 & 305060 & 0.7144 & 281795 & 0.6599 & 310024 & 0.7261 \\
MHE3 & 274000 & 250431 & 0.5865 & 244969 & 0.5737 & 256060 & 0.5997 & 239670 & 0.5613 & 259519 & 0.6078 \\
MHE4 & 234000 & 216661 & 0.5074 & 212598 & 0.4979 & 220830 & 0.5172 & 208638 & 0.4886 & 223383 & 0.5231 \\
MHE5 & 312000 & 281689 & 0.6597 & 274738 & 0.6434 & 288881 & 0.6765 & 268018 & 0.6277 & 293316 & 0.6869 \\
\hline
\end{tabular}

Table 8

Calculation of group utility index (GUI) of each alternative

$\begin{array}{cc}\bar{U}_{c 1}^{1}=[0.8703 \times 0.8414 \times 0.9005 \times 0.8139 \times 0.9193]^{1 / 5}=0.8682 & \bar{U}_{c 2}^{2}=[0.6956 \times 0.6775 \times 0.7144 \times 0.6599 \times 0.7261]^{1 / 5}=0.6943 \\ \bar{U}_{c 3}^{3}=[0.5865 \times 0.5737 \times 0.5997 \times 0.5613 \times 0.6078]^{1 / 5}=0.5856 & \bar{U}_{c 4}^{4}=[0.5074 \times 0.4979 \times 0.5172 \times 0.4886 \times 0.5231]^{1 / 5}=0.5067 \\ \bar{U}_{c 5}^{5}=[0.6597 \times 0.6434 \times 0.6765 \times 0.6277 \times 0.6869]^{1 / 5}=0.6585\end{array}$

Table 9

Incremental analysis with group utility

\begin{tabular}{|c|c|c|c|c|c|c|c|c|}
\hline \multirow{2}{*}{$\begin{array}{c}\mathrm{RC} \\
\left(C_{b i}^{*}\right)\end{array}$} & \multirow{2}{*}{$\begin{array}{c}\text { GUI } \\
\left(\begin{array}{c}U_{c i}^{i} \\
)\end{array}\right)\end{array}$} & \multirow{2}{*}{ MHEi } & \multirow{2}{*}{$\begin{array}{c}\text { Increment of } \\
\text { benefit } \\
\left(\Delta C_{b i}^{*}\right)\end{array}$} & Increment of & \multicolumn{4}{|c|}{ Incremental analysis between MHEi } \\
\hline & & & & $\operatorname{cost}\left(\Delta U_{c i}^{i}\right)$ & $3 \& 4$ & $5 \& 3$ & $2 \& 5$ & $2 \& 1 *$ \\
\hline 0.6258 & 0.8682 & MHE1 & 0.1827 & 0.1739 & & & \multirow{5}{*}{$1.3128>1$} & \multirow[t]{5}{*}{$1.0506>1$} \\
\hline 0.4431 & 0.6943 & MHE2 & 00470 & 00358 & & \multirow{4}{*}{$2.4307>1$} & & \\
\hline 0.3961 & 0.6585 & MHE5 & $0.04 / 0$ & & & & & \\
\hline 0.2189 & 0.5856 & MHE3 & 0.1772 & 0.0729 & & & & \\
\hline 0.0798 & 0.5067 & MHE4 & 0.1391 & 0.0789 & $1.7630>1$ & & & \\
\hline
\end{tabular}

\section{Conclusions}

In this paper, incremental analysis with group TOPSIS belonging to the class of MCDA techniques, is applied for solving material handling selection problems. Its applicability is illustrated with a real time example. Incremental analysis for MCDM is robust and effective in performance evaluation of material handling equipment by the application of group TOPSIS. In incremental analysis, the benefit-cost ratio or the cut-off ratio is the key factor for the selection of best alternative. To rank the alternatives the procedure of incremental analysis is repeated. If the monetary value of the benefit and cost is possible to achieve then the concerned problem can be solved by any technique of engineering problem the discrepancy between. It is possible due to absence of intangible factors. On the contrary, if the monetary value of the benefit and cost is not possible to achieve, in spite of presence of intangible factor, then the concerned problem is solved by technique of MCDM. In the problem of selection of material handling equipment discussed in the thesis paper, all the calculations have been done manually. It has been possible because of number of alternatives, criteria and DMs are limited viz. 5, 7 and 5 respectively. When the number of these goes up the solution of the problem should be solved efficiently by the execution of Microsoft Excel and MATLAB because the software can handle large number cells. Although the present method in this paper is illustrated by a material handling selection problem, it could also be applied to problems such as information project selection, machine selection, warehouse selection, vendor selection, material selection, and many other areas of management decision problems or strategy selection problems. 


\section{References}

Atmani, A., \& Dutta, S. P. (1996). Product design and materials handling system selection-A concurrent engineering approach. International Journal of Industrial Engineering-Theory, Applications and Practice, 3, 40-50.

Bernhard, R. H., \& Canada, J. R. (1990). Some problems in using benefit/cost ratios with the analytic hierarchy process. The Engineering Economist, 36 (1), 56-65.

Bhattacharya, A., Sarkar, B., \& Mukherjee, S. K. (2002). Material handling equipment selection under multi criteria decision making (MCDM) environment. Industrial Engineering Journal, 31(6), 17-25.

Castillo, I., \& Peters, B. A. (2002). Unit load and material-handling considerations in facility layout design. International Journal of Production Research, 40, 2955-2989.

Chittratanawat, S., \& Noble, J. S. (1999). An integrated approach for facility layout, P/D location and material handling system design. International Journal of Production Research, 37, 683-706.

Dey, B., Bairagi, B., Sarkar, B., \& Sanyal, S. (2012). MOORA based fuzzy multi-criteria decision making approach for supply chain strategy selection. International Journal of Industrial Engineering Computations, 3, 649-662.

Fulford, P., Jessena, S., Harris, C., \& Boucher, D. (2007). Sample acquisition, processing and handling systems for future Mars missions. Acta Astronautica, 61, $1061-1065$.

Golam, K., \& Hasin, M. A. A. (2012). Framework for benchmarking online retailing performance using fuzzy AHP and TOPSIS method. International Journal of Industrial Engineering Computations, 3(4), 561-576.

Goyal, S., \& Grover, S. (2012). A comprehensive bibliography on effectiveness measurement of manufacturing systems. International Journal of Industrial Engineering Computations, 3, 587-606.

Gupta, T. \& Dutta, S. P. (1994). Analyzing materials handling needs in concurrent/ simultaneous engineering. International Journal of Operations and Production Management, 14, 68-82.

Shih, H. S. (2008). Incremental analysis for MCDM with an application to group TOPSIS. European Journal of Operational Research, 186(2), 720-734.

Hwang, C. L., \& Yoon, K. (1981). Multiple attribute decision making methods and applications. New York: Springer-Verlag.

Karande, P. \& Chakraborty, S. (2013). Using MACBETH method for supplier selection in manufacturing environment. International Journal of Industrial Engineering Computations, 4, 259-272.

Lashkari, R. S., Boparai, R. \& Paulo, J. (2004). Towards an integrated model of operation allocation and materials handling selection in cellular manufacturing system. International Journal of Production Economics, 87(2), 115-139.

Paulo, J., Lashkari, R. S., \& Dutta, S. P. (2002). Operation allocation and materials-handling system selection in a flexible manufacturing system: a sequential modeling approach. International Journal of Production Research, 40, 7-35.

Raman, D., Nagalingam, S. V., Gurd, B. W., \& Lin, G. C. I. (2009). Quantity of material handling equipment-A queuing theory based approach. Robotics and Computer-Integrated Manufacturing, 25, 348-357.

Rembold, B. F., \& Tanchoco, J. M. A. (1994). Design justification of material handling systems. In: Tanchoco, J.M.A. (Ed.). Material Flow Systems in Manufacturing. Chapman \& Hall, UK, 54-72.

Ribeiro, J. F. F., \& Pradin, B. (1993). A methodology for cellular manufacturing design. International Journal of Production Research, 31, 235-250.

Saaty, T. L. (1980). The Analytic Hierarchy Process. McGraw-Hill, NY.

Sharma, S. C. (1999). Production Management. Khanna Publishers.

Sujono, S., \& Lashkari, R. S. (2007). A multi-objective model of operation allocation and material handling system selection in FMS design. International Journal of Production Economics, 105, 116-133.

Sule, D.R. (199). Manufacturing Facilities: Location, Planning, and Design. PWS, Boston. 